\title{
ÉPOCA DE SEMEADURA, FENOLOGIA E CRESCIMENTO DE PLANTAS DE FISÁLIS NO SUL DO BRASIL ${ }^{1}$
}

\author{
DÉBORA LEITZKE BETEMPS ${ }^{2}$, JOSÉ CARLOS FACHINELLO ${ }^{3}$, \\ CLÁUDIA SIMONE MADRUGA LIMA ${ }^{4}$, SIMONE PADILHA GALARÇA4, \\ ANDREA DE ROSSI RUFATO 5
}

RESUMO- Os objetivos do presente trabalho foram avaliar o comportamento fenológico e os componentes do crescimento de plantas de fisális (Physalis peruviana L.) em função de três épocas de semeadura, na região de Pelotas-RS. São determinados as datas de ocorrência, os dias após a emergência (DAE) e a soma térmica (GD) para os seguintes estádios: folhas verdadeiras, primeira ramificação, brotação floral, botões florais, flores abertas, formação de brotos basais, frutos caídos, início de queda das folhas e colheita. Quinzenalmente, a partir do transplante, foram realizadas avaliações de comprimento do ramo principal, número total de folhas do ramo principal, número de flores e frutos por planta. Nas condições edafoclimáticas de Pelotas, as plantas de fisális, oriundas da semeadura em novembro, necessitaram de menor número de DAE para completar os estádios fenológicos; contudo, esta tendência não se manteve para GD. A semeadura de fisális realizada no início do mês de setembro resultou em plantas com maior crescimento vegetativo e número de frutos, bem como com características de crescimento e de produção semelhantes às principais regiões de cultivo.

Termos para indexação: Physalis peruviana, desenvolvimento, estádios fenológicos.

\section{TIME OF SOWING, PHENOLOGY AND GROWTH OF CAPE GOOSEBERRY PLANTS IN SOUTHERN BRAZIL}

\begin{abstract}
The objectives of this study were to evaluate the phenological behavior and components of plant growth cape gooseberry (Physalis peruviana L.) according to three sowing dates in Pelotas, RS. Being determinated dates of occurrence, days after emergence (DAE) and thermal (degree-days) for the following stages: true leaves, first branching, sprouting flowers, bud flowers, open flowers, basal shoot formation, fallen fruit, early leaf fall, and harvest. Every two weeks from the transplant, the main branch length, number of leaves of the main stem, number of flowers and fruits per plant were evaluated. At conditions of Pelotas, cape gooseberry plants originated in November sowing required fewer days after emergence to complete the phenological stages, however, this trend was not maintained for degree days. Cape gooseberry performed sowing early in the month of September resulting in plants with more vegetative growth, more number of fruits, growth and production characteristics similar to the main growing regions.
\end{abstract}

Index terms: Physalis peruviana. development. phenological stages.

1(Trabalho 292-13). Recebido em: 22-08-2013.Aceito para publicação em: .17-01-2014. Apoio: CNPQ.

${ }^{2} \mathrm{Dr}^{\mathrm{a}}$ Prof. Adj. Universidade Federal da Fronteira Sul- Campus Laranjeiras do Sul. BR $158 \mathrm{~km} 405$ Cep 85301- Laranjeiras do Sul/ Paraná, Brasil. E-mail: debora.betemps@uffs.edu.br

${ }^{3}$ Dr. Prof. Titular, Fruticultura Clima Temperado, Depto. Fitotecnia/FAEM/UFPel, Pelotas/RS. E-mail: jfachi@ufpel.edu.br

${ }^{4} \mathrm{Dr}^{\mathrm{a}}$ Extensionista da Emater/RS. Rua Felix da Cunha 626, cep 96010-000 Pelotas/RS, Brasil. E-mail sgalarca@superig.com.br; claudialim@hotmail.com.

${ }^{5} \mathrm{Dr}^{\mathrm{a}}$ Pesquisadora da Embrapa Uva e Vinho. Estação Experimental de Fruticultura Temperada. BR 285, Morro Agudo cep 95200-000, Vacaria/RS Brasil E mail: andrea@cnpuv.embrapa.br 


\section{INTRODUÇÃO}

A fenologia das plantas diz respeito ao período e à duração de eventos como a floração, a frutificação e a emissão foliar, sendo muitas vezes pouco conhecida para muitas espécies cultivadas fora de sua área natural (PALIOTO et al., 2007).

$\mathrm{Na}$ implantação de novas espécies para cultivo, como no caso da fisális, é essencial o conhecimento da fenologia para o desenvolvimento de adequadas práticas de gestão a serem aplicadas durante o ciclo de vida da planta (RAMIREZ et al., 2013). Para Sato et al. (2008), o comportamento fenológico possibilita ao agricultor prever o desenvolvimento da cultura e as épocas em que será necessária maior demanda de mão de obra e tratos culturais.

Esta planta tem despertado grande interesse em todo o mundo, pois produz fruto medicinal, nutritivo e propriedades farmacêuticas. Componentes de saúde relacionados incluem antioxidantes, os ácidos gordos poli insaturados, as vitaminas A, B, C, E e K1, além da presença de minerais essenciais (PUENTE et al., 2011). Devido a estes atributos, a fruta está sendo alvo de comercialização e, progressivamente, difundida no mercado internacional e nacional (CHAVES et al., 2005). Trata-se de uma solanácea, e a maior parte do manejo, no Sul do Brasil, ainda é feito de acordo com a cultura do tomateiro. A planta é considerada arbustiva e pode atingir dois metros de altura, o fruto constitui-se em uma baga carnosa, em forma de globo, com diâmetro que oscila entre 1,25 e $2,50 \mathrm{~cm}$ e peso entre 4 e $10 \mathrm{~g}$ (RUFATO et al., 2008).

Em frutíferas, que são tidas como anuais, e para as quais o principal método de propagação é por sementes, como a fisális, a época de semeadura e de transplante são fatores determinantes na duração do ciclo fenológico. Conforme Antunes et al. (2008), as épocas de semeadura e de transplante devem permitir a realização do cultivo no período mais favorável, em termos de disponibilidade hídrica, de calor e de luminosidade, ao crescimento e ao desenvolvimento das plantas, assegurando, assim, menor risco aos produtores e aos agentes financeiros que investem em novas culturas.

Estudos de época de semeadura e fenologia dessa espécie fazem-se necessários, pois fornecem informações importantes sobre a duração média das diferentes fenofases bem como adaptação às condições edafoclimáticas locais, permitindo o adequado manejo da cultura. Deste modo, objetivouse com este trabalho avaliar o comportamento fenológico e os componentes do crescimento de plantas de fisális (Physalis peruviana L.) em função de três épocas de semeadura, na região de Pelotas-RS.

\section{MATERIAL E MÉTODOS}

O experimento foi instalado no município do Capão do Leão-RS, latitude $31^{\circ} 52^{\prime} 00^{\prime}$ ' S, longitude $52^{\circ} 21^{\prime} 24$ " W e altitude de 13,24 metros. O clima da região caracteriza-se como temperado úmido, com verões quentes, conforme a classificação de Köppen, do tipo "Cfa". A região possui temperatura média e chuva anual de $17,9^{\circ} \mathrm{C}$ e $1.500 \mathrm{~mm}$, respectivamente, sendo os dados obtidos da Estação Agroclimatológica da UFpel (2009) (Figura 1). O solo onde foi implantado o experimento é classificado como Argissolo Vermelho-Amarelo.

O trabalho foi conduzido entre agosto de 2007 e novembro de 2008. As sementes que deram origem às plantas de fisális (Physalis peruviana L.) são oriundas do Centro de Ciências Agroveterinárias da Universidade do Estado de Santa Catarina, em Lages-SC.

Para obtenção de mudas de fisális, a semeadura foi realizada em condições de telado, em bandeja de poliestireno expandido, com 128 células preenchidas com substrato comercial Plantmax ${ }^{\circledR}$, em três épocas (04-09-2007, 26-11-2007 e 17-02-2008) Estas foram mantidas em telado com $30 \%$ de sombreamento e sob irrigação de microaspersão intermitente.

O transplante das mudas aconteceu depois de realizada a correção do solo quanto ao $\mathrm{pH}$ $(6,0)$ e adubação de acordo com análise do solo, sendo realizado a campo, quando as plantas estavam no estádio de duas folhas verdadeiras e, aproximadamente, $20 \mathrm{~cm}$ de comprimento. As plantas foram tutoradas, utilizando estacas de bambu, com espaçamento de $1 \mathrm{~m}$ entre plantas e 3,5 $\mathrm{m}$ entre linhas. O sistema de irrigação adotado foi por gotejamento. Não foram realizadas atividades de poda, desponte, desbrote e/ou raleio.

As avaliações fenológicas foram realizadas a partir da emergência das plântulas, conforme a metodologia adaptada de Gouveia e Felfili (1998). O início de cada evento fenológico foi determinado quando $30 \%$ da população de plantas apresentaram mudança, sendo avaliados os seguintes estádios: Estádio 1- folhas verdadeiras: plântulas com um par de folhas verdadeiras totalmente expandidas e aproximadamente $20 \mathrm{~cm}$ de comprimento; Estádio 2- ramificação: as plantas com as primeiras bifurcações do talo principal; Estádio 3- gemas florais: plantas com gemas florais esféricas e pubescentes, de aproximadamente $10 \mathrm{~mm}$; no ramo principal, as gemas estavam acompanhadas de uma folha e uma ramificação, e nos ramos secundários, 
acompanhadas de uma folha de maior tamanho com outra de menor tamanho; Estádio 4- botões florais: plantas com botões muito proeminentes, a corola sobressai-se ao cálice, sendo identificado como início de botões florais; Estádio 5-flores abertas: plantas com flores em dois estádios, com a corola parcialmente ou complemente aberta, ou seja, início de flores abertas; Estádio 6- formação de brotos basais: início da formação de brotos na base do ramo principal; Estádio 7- início da queda das folhas e frutos: desprendimento natural das primeiras folhas senescentes (coloração amarela) e dos frutos; e Estádio 8- colheita: coloração do cálice dos frutos a partir do amarelo-esverdeado.

A partir das datas de ocorrência e dias após a emergência (DAE) dos eventos fenológicos, foram calculados os graus-dia (GD) acumulados para alcançar o início de cada fase fenológica, considerando-se $6,3^{\circ} \mathrm{C}$ como temperatura base (SALAZAR et al., 2008). O cálculo dos GDs necessários para completar cada estádio fenológico foi feito segundo a expressão:

$$
\mathrm{GD}=\sum_{\mathrm{i}=1}^{\mathrm{n}}(\mathrm{Ti}-\mathrm{Tb})
$$

em que, GD são acumulados no período considerado; Ti é temperatura média diária $\left({ }^{\circ} \mathrm{C}\right) ; \mathrm{Tb}$ é a temperatura base $\left({ }^{\circ} \mathrm{C}\right)$; n é o número de dias do período considerado.

As observações de crescimento ocorreram quinzenalmente a partir do transplante, totalizando 20 avaliações e alcançando 300 dias após o transplante (DAT). Foram realizadas as seguintes avaliações: comprimento do ramo principal (CR) (cm): determinado a partir do nível do solo, com auxílio de fita métrica; número total de folhas do ramo principal: contagem do número total de folhas; número de flores: contagem do número total de flores abertas por planta; e número médio de frutos por planta. $\mathrm{O}$ delineamento experimental unifatorial (dois níveis: 1 - semeadura em 04-092007, e 2 - semeadura em 26-11-2007), foi em blocos casualizados. Cada bloco foi representado por 80 plantas, totalizando 240 plantas por data de semeadura. A terceira época de semeadura foi desconsiderada porque houve morte das plantas por formação de geada.

Foi procedida a análise de variância pelo teste F e, quando o efeito de tratamento foi significativo, realizou-se o teste de Tukey para a comparação de médias, ao nível de $5 \%$ de probabilidade de erro. Foram determinadas as curvas de crescimento das variáveis respostas que foram avaliadas por modelos de regressão $(p \leq 0,05)$. Para análise de variância, os dados expressos em número foram transformados em $y=\sqrt{x+k}$, em que, $\mathrm{k}=1$, se $\mathrm{x}>15, \mathrm{k}=0,5$, se

$0 \leq \mathrm{X} \leq 15$ e reconvertidos em $(x+k)^{2}$.

\section{RESULTADOS E DISCUSSÃO}

Para as duas primeiras épocas de semeadura, as plantas completaram os estádios estabelecidos, enquanto para a terceira época de semeadura, o ciclo não foi completo, devido à formação de geada.

As plantas de fisális necessitaram, em média, de 54 dias após a emergência ou 693GD, para estarem aptas ao transplante. Depois do transplante, foram necessários 77 dias e 212GD para iniciar a ramificação; 85 dias e 217GD para início de gemas florais; 106 dias e 208GD para início de botões florais; 108 dias e 49GD para abertura das flores; 111 dias e 44GD para começar a formação de brotos basais; 131 dias e 303GD para senescência de folhas e frutos caídos, e 150 dias após a emergência para o início da colheita e 277GD (Tabelas 01 e 02).

Verifica-se ainda, na Tabela 01 , que a primeira época de semeadura necessitou de maior número de dias para atingir cada estádio fenológico. Paras as duas primeiras épocas de semeadura, nota-se certa regularidade, em número de dias, para a troca do estádio 4 até o estádio 6, quando as mudanças ocorreram a cada três dias. Já as mudanças dos estádios 7 até o 8 aconteceram a cada 21 dias para a época 1 , e a cada 18 dias para a época 2 . Até o estádio 4 (início de botões florais), houve variações para a troca de estádio, provavelmente, em função da época de semeadura. As plantas oriundas da época 2 (26-11-2007) apresentavam período vegetativo mais curto do que aquelas oriundas da época 1 (04-09-2007). Conforme Salazar et al. (2008a), em Physalis peruviana L., o crescimento vegetativo é favorecido com o fotoperíodo e a temperatura, o que foi evidenciado neste experimento para as plantas oriundas da primeira época de semeadura.

A segunda época de semeadura necessitou de menor número de dias após a emergência para completar os estádios fenológicos, e esta tendência manteve-se para graus-dia (Tabelas 01 e 02). A ocorrência dos principais estádios fenológicos de $P$. peruviana variou nos estudos de Chaves et al. (2005), em função do ambiente de produção (local, temperatura, época de plantio e manejo).

O maior acúmulo de graus-dia foi verificado da emergência ao transplante, com valores de 723 GD para a época de semeadura 1; 823 GD para época de semeadura 2, e 529 GD para época de semeadura 
3. É importante salientar que, para iniciar o estádio de gemas florais, nas duas primeiras épocas de semeadura, foram necessários aproximadamente 1.100 GD. As variações de acúmulo térmico observadas entre as épocas de semeadura estão relacionadas com o período em que foi realizada a semeadura (final de inverno para a época 1; primavera para a época 2 , e verão para a época 3 ); logo, conforme se aproximou o verão, ocorreu, obviamente, aumento das temperaturas e, assim, do acúmulo térmico.

Conforme Lima et al. (2010), o cultivo de fisális em locais com temperaturas elevadas (aproximadamente $30^{\circ} \mathrm{C}$ ) tende a favorecer o crescimento vegetativo; já em condições de clima ameno (aproximadamente $14^{\circ} \mathrm{C}$ ), existe estimulação à floração, frutificação e brotação, e o ciclo tende a ser mais curto. Em relação ao crescimento de plantas, conforme pode ser verificado na Tabela 03 , na primeira época de semeadura, o comprimento médio do ramo principal das plantas de fisális foi maior do que na segunda época. Aos 300 DATs, o comprimento do ramo principal foi de 95 e $60 \mathrm{~cm}$, respectivamente (Figura 02 a).

Até os 120 DATs, o ramo principal apresentou incremento quinzenal do comprimento de aproximadamente $10 \mathrm{~cm}$ para época de semeadura 1, e $5 \mathrm{~cm}$ para época de semeadura 2 (Figura 02 a). Após este período, houve estabilização no incremento do comprimento. Estes resultados podem estar relacionados com a queda da temperatura média mensal, a partir de fevereiro de 2008.

Quanto ao número total de folhas do ramo principal, as maiores médias foram observadas na primeira época de semeadura (29 folhas), enquanto, na segunda época de semeadura, a média de número de folhas do ramo principal foi 17 (Figura 02 a e Tabela 03). Observa-se crescimento linear no número de folhas até os 105 DATs para época de semeadura 1, e 60 DATs para época de semeadura 2; contudo, esta variável apresentou uma resposta de crescimento polinomial para as duas épocas. Verificou-se redução acentuada do número de folhas aos 120 e 165 DATs, para primeira época de semeadura, e aos 75 e 105 DATs na segunda época de semeadura. Estes períodos correspondem ao início da colheita e à ocorrência da primeira geada, respectivamente.

O pico de floração ocorreu aos 150 e 165 DATs para primeira e segunda épocas de semeadura, respectivamente (Figura $02 \mathrm{~b}$ ). Segundo Fischer e Lüdders (2002), o pico de floração das fisális ocorre entre 150 e 170 DATs, variando de acordo com o manejo e as condições edafoclimáticas. Plantas da primeira época de semeadura exigiram um período maior entre o transplante e a floração. A floração teve início a partir de 60 dias após o transplante para época 1 e 45 dias para época 2, e manteve-se até o final do experimento (300 DATs).

Entre as épocas de semeadura, é bastante pronunciada a diferença de número de flores; nos períodos de 90 até 150 DATs e dos 180 aos 300 DATs, havia cerca de 20 flores planta $^{-1}$ a mais para a primeira época de semeadura (Figura 02 b). O maior número de flores por planta na primeira época de semeadura se deve, provavelmente, aos períodos nos quais ocorreu o pico de floração (em abril, antes da geada, para época 1, e em junho, após a geada, para época 2). Deve-se, também, considerar o maior número de ramificações secundárias e terciárias que as plantas da época 1 apresentavam. Chaves et al. (2005), em Pelotas, constataram, em plantio de fisális oriundo da micropropagação, que o pico de floração ocorreu em março, com uma média de 42 flores planta ${ }^{-1}$, os valores reportados neste trabalho são superiores para as duas épocas de colheitas observadas.

Na primeira época de semeadura, a colheita iniciou-se em fevereiro, com pico de frutificação em junho, aos 195 DATs (Figura 02 b), sendo a média de frutos planta ${ }^{-1}$ de 72 . Na segunda data de semeadura, o pico de frutificação foi em agosto, aos 210 DATs; a média de frutos por planta foi de 53 (Figura $02 \mathrm{~b}$ e Tabela 03). Houve ocorrência de intenso ataque de lepidóptera, Heliothis virescens (F.) (lagarta-das-maçãs), sendo, por isso, desconsideradas a primeira colheita, na época 1, e as últimas colheitas, na época 2. 
TABELA 1 - Número de dias após a emergência (DAE) para as plantas de Physalis peruviana atingirem os principais estádios fenológicos em função de três épocas de semeadura. Pelotas-RS, 2013.

\begin{tabular}{cccccccccc}
\hline Época de & \multicolumn{10}{c}{ Estádios } \\
\cline { 2 - 10 } semeadura & $\mathbf{1}$ & $\mathbf{2}$ & $\mathbf{3}$ & $\mathbf{4}$ & $\mathbf{5}$ & $\mathbf{6}$ & $\mathbf{7}$ & $\mathbf{8}$ & $\mathbf{9}$ \\
\hline $\mathbf{1}(\mathbf{0 4 - 0 9 - 2 0 0 7 )}$ & $67 \mathrm{a}$ & $88 \mathrm{a}$ & $93 \mathrm{a}$ & $116 \mathrm{a}$ & $119 \mathrm{a}$ & $122 \mathrm{a}$ & $143 \mathrm{a}$ & $164 \mathrm{a}$ & -- \\
$\mathbf{2}(\mathbf{2 6 - 1 1 - 2 0 0 7 )}$ & $56 \mathrm{~b}$ & $66 \mathrm{~b}$ & $77 \mathrm{~b}$ & $95 \mathrm{~b}$ & $98 \mathrm{~b}$ & $101 \mathrm{~b}$ & $119 \mathrm{~b}$ & $137 \mathrm{~b}$ & ----- \\
$\mathbf{3}(\mathbf{1 7 - 0 2 - 2 0 0 8 )}$ & $40 * *$ & ----- & ----- & ----- & ----- & ----- & ----- & ----- & $123 * * *$ \\
\hline Média & 54 & 77 & 85 & 106 & 108 & 111 & 131 & 150 & ----- \\
\hline Desv-Padrão & 1,60 & 5,55 & 1,31 & 4,80 & 4,84 & 4,84 & 6,97 & 9,80 & ----- \\
\hline
\end{tabular}

*Estádios 1= Transplante; 2= Início da ramificação; $3=$ Início de gemas florais; 4= Início de botões florais; $5=$ Início de flores abertas; $6=$ Início da formação de brotos basais; $7=$ Início de frutos caídos e folhas senescentes; $8=$ Início da Colheita; 9= Morte das plantas.

**A terceira época de semeadura foi desconsiderada porque houve morte das plantas por formação de geada.

***Médias seguidas pela mesma letra minúscula na coluna não diferem entre si, pelo teste de Tukey $(\mathrm{p} \leq 0,05)$.

TABELA 2 - Graus-dia (GD) acumulados para completar os principais estádios fenológicos de plantas de Physalis peruviana, em função de três datas de semeadura. Pelotas-RS, 2013.

\begin{tabular}{ccccccccccc}
\hline Época de & \multicolumn{10}{c}{ Estádios } \\
\cline { 2 - 12 } semeadura & $\mathbf{1}$ & $\mathbf{2}$ & $\mathbf{3}$ & $\mathbf{4}$ & $\mathbf{5}$ & $\mathbf{6}$ & $\mathbf{7}$ & $\mathbf{8}$ & $\mathbf{9}$ \\
\hline $\mathbf{1}(\mathbf{0 4 - 0 9 - 2 0 0 7 )}$ & $725 \mathrm{~b}$ & $275 \mathrm{a}$ & $70 \mathrm{~b}$ & $364 \mathrm{a}$ & $58 \mathrm{a}$ & $40 \mathrm{~b}$ & $313 \mathrm{a}$ & $292 \mathrm{a}$ & ------- \\
$\mathbf{2}(\mathbf{2 6 - 1 1 - 2 0 0 7 )}$ & $823 \mathrm{a}$ & $149 \mathrm{~b}$ & $164 \mathrm{a}$ & $251 \mathrm{~b}$ & $41 \mathrm{~b}$ & $47 \mathrm{a}$ & $222 \mathrm{~b}$ & $233 \mathrm{~b}$ & ------ \\
$\mathbf{3}(\mathbf{1 7 - 0 2 - 2 0 0 8 )})$ & $529 * *$ & ---- & ----- & ------ & ------ & ----- & ----- & ----- & $385^{* *}$ \\
\hline Média & 692 & 212 & 217 & 208 & 49,90 & 44 & 303 & 277,88 & ------ \\
\hline Desv.- Padrão & 3,87 & 3,27 & 2,93 & 1,98 & 2,67 & 1,17 & 1,83 & 1,61 & ----- \\
\hline
\end{tabular}

* Estádios 1= Transplante; 2 = Início da ramificação; $3=$ Início de gemas florais; 4= Início de botões florais; $5=$ Início de flores abertas; 6= Início da formação de brotos basais; $7=$ Início de frutos caídos e folhas senescentes; 8= Início da Colheita; 9= Morte das plantas.

**A terceira época de semeadura foi desconsiderada porque houve morte das plantas por formação de geada.

***Médias seguidas pela mesma letra minúscula na coluna não diferem entre si, pelo teste de Tukey $(\mathrm{p} \leq 0,05)$.

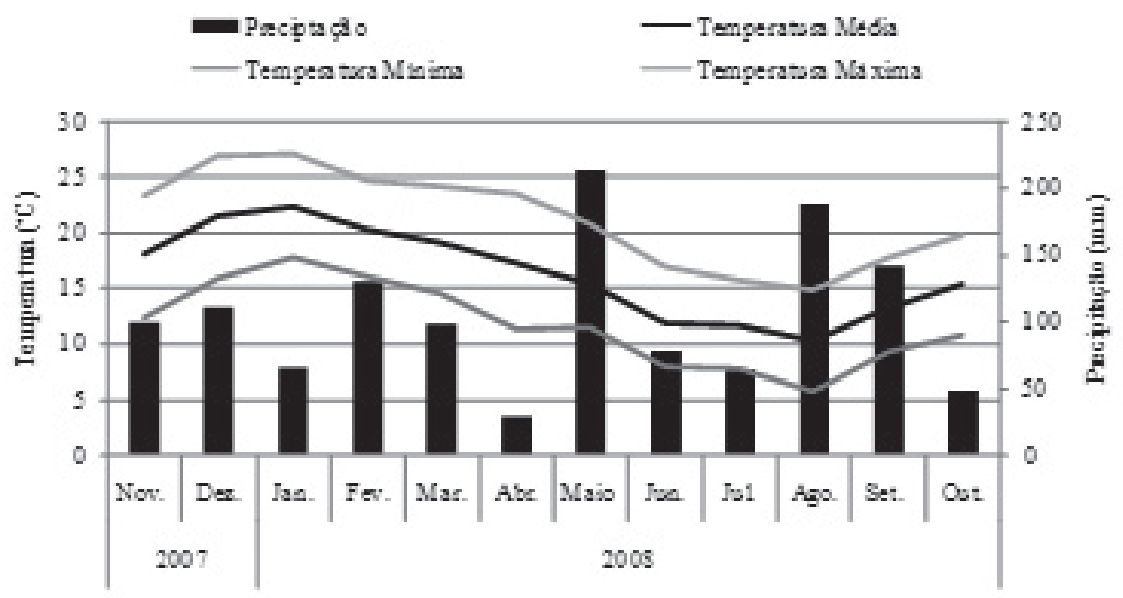

Mess

FIGURA 1- Dados climáticos (precipitação, temperaturas mínima, média e máxima) nos anos de 2007 e 2008. Pelotas-RS, 2013. 

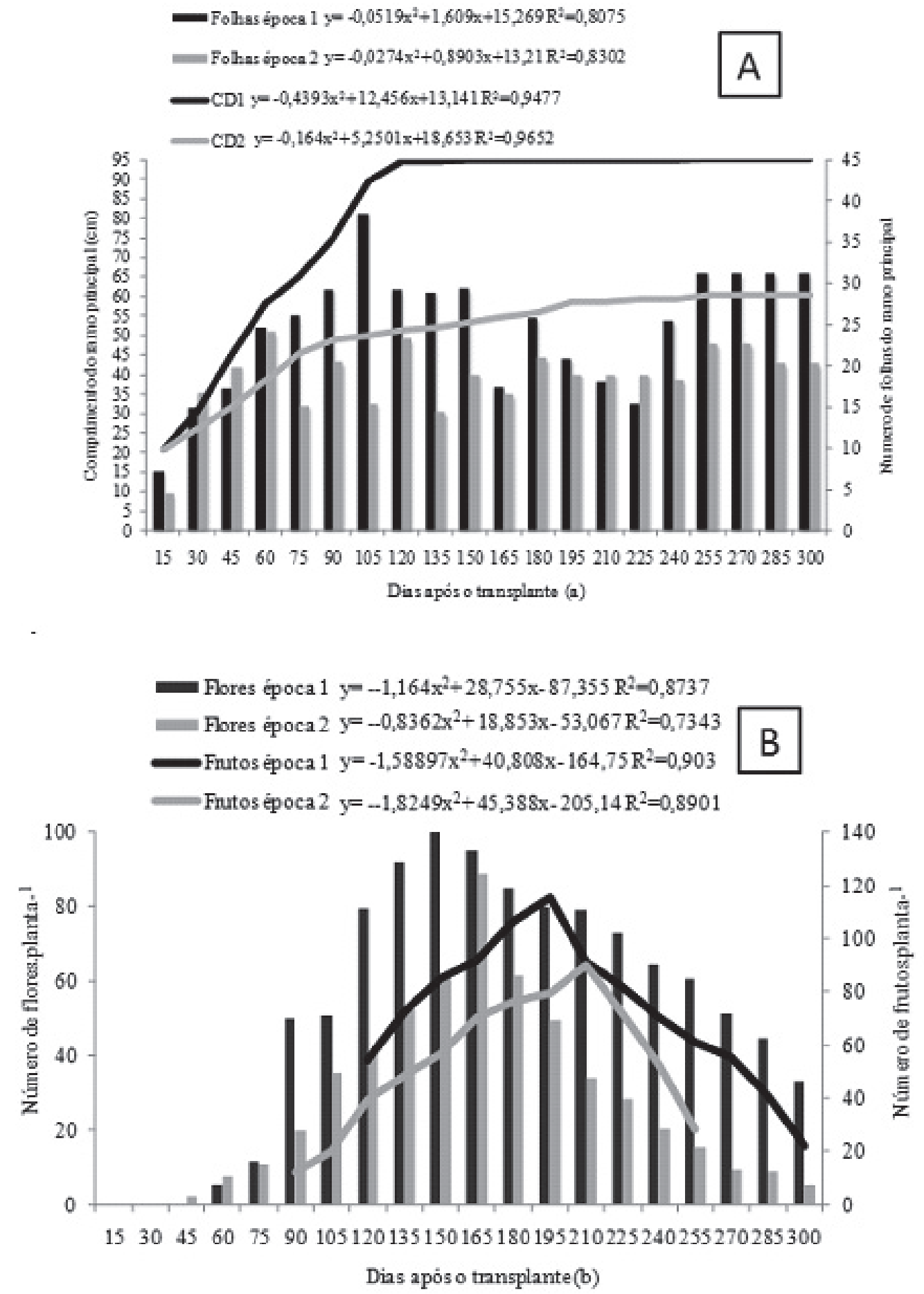

FIGURA 2 - (A) Comprimento e número de folhas do ramo principal de plantas de Physalis peruviana, em função de duas épocas de semeadura. Pelotas-RS, 2009.

* $\mathrm{CD} 1=$ Comprimento do ramo principal e época de semeadura 1 (04-09-2007); $\mathrm{CD} 2=$ Comprimento do ramo principal e época de semeadura 2 (26-11-2007).

(B) Número de flores e frutos por planta de Physalis peruviana, em função de duas épocas de semeadura (1- 04-09-2007; 2- 26-112007). Pelotas-RS, 2013. 
TABELA 3 - Valores médios de comprimento, diâmetro e número de folhas do ramo principal, número de brotos, de flores e frutos por planta de Physalis peruviana, em função de duas épocas de semeadura. Pelotas-RS, 2013.

\begin{tabular}{ccccc}
\hline Épocas de & \multicolumn{2}{c|}{ Ramo principal } & \multicolumn{2}{c}{ Número planta $^{-1}$} \\
\cline { 2 - 5 } semeadura & Comprimento (cm) Número de Folhas & Flores & Frutos $^{-}$ \\
\hline $\mathbf{1}(\mathbf{0 4 - 0 9 - 2 0 0 7 )}$ & $80,15 \mathrm{a}$ & $29,88 \mathrm{a}$ & $60,19 \mathrm{a}$ & $71,99 \mathrm{a}$ \\
$\mathbf{2}(\mathbf{2 6 - 1 1 - 2 0 0 7 )}$ & $50,50 \mathrm{~b}$ & $17,99 \mathrm{~b}$ & $29,52 \mathrm{~b}$ & $53,48 \mathrm{~b}$ \\
\hline Média Geral & 65,32 & 23,93 & 44,85 & 62,73 \\
\hline CV (\%) & 16,08 & 12,33 & 17,90 & 18,75 \\
\hline
\end{tabular}

*Médias seguidas pela mesma letra minúscula na coluna não diferem entre si, pelo teste de Tukey $(\mathrm{p} \leq 0,05)$.

\section{CONCLUSÃO}

1-A semeadura de fisális realizada no início do mês de setembro resulta em plantas com maior crescimento vegetativo e número de frutos, sendo as características de crescimento e produtivas semelhantes às principais regiões de cultivo desta espécie.

2-A semeadura realizada no mês de novembro reduz o número de dias após a emergência para completar os estádios fenológicos estabelecidos.

3-O acúmulo de graus-dia necessário para completar os estádios fenológicos é variável entre as datas de plantio.

\section{REFERÊNCIAS}

ANTUNES, L.E.C.; GONÇALVES, E.D.; RISTOW, N.C.; CARPENEDO, S.; TREVISAN, R. Fenologia, produção e qualidade de frutos de mirtilo. Pesquisa Agropecuária Brasileira, Brasília, v.43, p.10111015, 2008.

CHAVES, A.C.; SCHUCH, M.W.; ERIG, A.C. Estabelecimento e multiplicação in vitro de Physalis peruviana L. Revista Ciência e Agrotecnologia, Lavras, v. 29, p.1.281-1.287, 2005.

FISCHER, G.; LÜDDERS, P. Efecto de la altitud sobre el crecimiento y desarrollo vegetativo de la uchuva (Physalis peruviana L.). Revista Comalfi, Bogotá, v.29, p.1-10, 2002.

GOUVEIA, G.P.; FELFILI, J.M. Fenologia de comunidades de cerrado e de mata de galeria no Brasil Central. Revista Árvore, Viçosa, MG, v.22, p.443-450, 1998.

LIMA, C.S.M.; GONÇALVES, M.A.; TOMAZ, Z.F.P.; FACHINELLO, J.C.; RUFATO, A.R. Sistemas de tutoramento e épocas de transplante de physalis. Ciência Rural, Santa Maria, v.40, p.1 $-8,2010$.
PALIOTO, F.G.; SUGIOKA, D.K.; CODA, J.;ZAMPAR, R.; LAZARIN, M.O.; LOYOLA, M.B.P.;FILHO, R.C.J. Fenologia de espécies arbóreas no Câmpus da Universidade Estadual de Maringá . Revista Brasileira de Biociências, Porto Alegre, v. 5, p. 441-443, 2007.

PUENTE, L.A.; PINTO-MUÑOZ, S.A.; CASTRO, E.S.; CORTÉS, M. Physalis peruviana Linnaeus, the multiple properties of a highly functional fruit: a review. Food Research International, Barking, v.44, 1.733-1.740. 2011.

RAMÍREZ, F.; FISCHER, G.; DAVENPORT, T.L.; PINZÓN, J.C.A.; ULRICHS, C. Cape gooseberry (Physalis peruviana L.) phenology according to the $\mathrm{BBCH}$ phenological scale. Scientia Horticulturae, Amsterdam, v.162, 39-42. 2013.

RUFATO, L.; RUFATO, A.R.; SCHELEMPER,C.; LIMA,C.S.M.; KRETZSCHMAR, A. A. Aspectos técnicos da cultura da Physalis. Lages: CAV/ UDESC; Pelotas: UFPel, 2008. 100p.

SALAZAR, M.R.; JONES, J.W.; CHAVES, B.; COOMAN, A.; FISCHER, G. Base temperature and simulation model for nodes appearance in cape gooseberry (Physalis peruviana L.). Revista Brasileira de Fruticultura, Jaboticabal, v. 30, p. 862-867,2008.

SALAZAR, M.R.; JONES, J.W.; CHAVES, B.; COOMAN, A. A model for the potential production and dry matter distribution of cape gooseberry (Physalis peruviana L.). Scientia Horticulturae, Amsterdam, v.115, p.142-148, 2008a.

SATO, A.J.; JUBILEU, B.; EZEQUIEL, C.S; ROBERTO, S.R. Fenologia e demanda térmica das videiras Isabel e Rubea sobre diferentes portaenxertos na região norte do Paraná. Semina. Ciências Agrárias, Londrina, v. 29, p. 283-292, 2008. 